\title{
Proposal of Inappropriate Insulin Syndrome Screened with Standard Cookie Meal, A Possible Accelerating and Common Factor for Corona 19, Metabolic Syndrome and Obesity and its Clinical Significance
}

\author{
Y Harano $^{1-4 *}$, E Ikemoto $^{1}$, M Nakahira ${ }^{1}$ and A Harano ${ }^{1}$ \\ ${ }^{1}$ Niseikai Center for Lifestyle-related diseases, Japan \\ ${ }^{2}$ Nichidan Research Laboratory, Japan \\ ${ }^{3}$ Visiting investigator, National Cardiovascular Center, Japan \\ ${ }^{4}$ Visiting professor, Osaka College of Rehabilitation, Japan \\ *Corresponding author: Y Harano, Niseikai Center for Lifestyle-related diseases, Japan
}

\section{ARTICLE INFO}

Received: 幽 March 08, 2021

Published: 慧 March 15, 2021

Citation: Y Harano, E Ikemoto, M Nakahira, A Harano. Proposal of Inappropriate Insulin Syndrome Screened with Standard Cookie Meal, A Possible Accelerating and Common Factor for Corona19, Metabolic Syndrome and Obesity and its Clinical Significance. Biomed J Sci \& Tech Res 34(3)-2021. BJSTR. MS.ID.005568.

Keywords: Inappropriate Insulin Syndrome; Insulin Resistance; Good Insulin Action; Bad Insulin Action; Postprandial Dyslipidemia; Hypoinsulinemia; Hyper Insulinemia; Corona 19; Glucose Clearance; Insulin Suppression Test; Insulin Sensitivity

\begin{abstract}
Inappropriate insulin syndrome is proposed based on the Whole Body Glucose Clearance (WBGC), which reflects the whole body glucose metabolism (good action) under own insulin. Using standard meal test, WBGC for well controlled type 2 diabetes with basic hypoglycemic agents showed $33 \%$ reduced $(5.07 \pm 0.33 \mathrm{ml} / \mathrm{kg} / \mathrm{min})$ over control without change of serum insulin level, suggesting the presence of insulin resistance. Reduced good insulin action is the key metabolic marker for obesity, metabolic syndrome and type 2 diabetes, and is known to be present in HT, hyperlipidemia, cardiovascular diseases and probable in Corona 19 as a deteriorating factor. Compensating hyperinsulinemia exhibits enhancing bad insulin action, reabsorption of renal $\mathrm{Na}$ and uric acid causing HT and hyperuricemia, inhibiting VLDL release from liver leading to NAFLD. Combination of this excessive bad insulin action is also included in this syndrome. In order to locate the decreased WBGC, simplified insulin suppression test [2] using Sand statin combined use of the Cookie meal gives the whole body(4h), muscle( $2 \mathrm{~h})$ and the difference corresponding to the hepatic glucose clearance against exogenous insulin. The excessive bad insulin action is not proven in Corona 19. Holding Tokyo Olympic as a symbol of exercise and sport, seeking ideal lifestyle, active to maintain adequate body shape, with modest drinking and no smoking, which stimulate basic good action of insulin to conquer Corona19, together with reducing metabolic syndrome as well as lifestylerelated diseases and promoting longevity of healthy life.
\end{abstract}

\section{Introduction}

Insulin resistance is a well-known concept but requires complicated tests like euglycemic glucose clump [1] or more simplified insulin suppression test [2] using Sand statin. This reflects mainly glucose clearance in muscle (adipose tissue), but in the latter method, a part of liver is involved because of the initial hyperglycemia allows hepatic glucose utilization in part through glucokinase. A proposed oral standard cookie meal containing $75 \mathrm{~g}$ wheat starch with $15 \%$ maltose (Cookie meal test [3], Saraya,
Japan) is thought to be constantly converted into blood glucose over 2 hours in man, therefore serves to screen whole body glucose clearance using $2 \mathrm{~h}$ steady state plasma glucose level $(75 \mathrm{~g}$ glucose/2h plasma glucose/kg BW, min). This approximates whole body glucose clearance (liver \& muscle, non-insulin dependent brain) under endogenous insulin. A regular 75g OGTT using liquid glucose (Toleran G) contains about 33\% free glucose other than partial hydrolysate of starch and not suitable for the constant supply of glucose for the whole body, although $2 \mathrm{~h}$ glucose level is almost 
the same as the above cookie meal. A cut-off point for the diagnosis of diabetes over $200 \mathrm{mg} / \mathrm{dl}$, IGT, $140-200 \mathrm{mg} / \mathrm{dl}$ and normal below $140 \mathrm{mg} / \mathrm{dl}$ is therefore justified from the above proposed concept of whole body glucose clearance. However, this concept has not been shown before.

\section{Conclusion}

In well-controlled type 2 diabetes with basic hypoglycemic agents (biguanides, $\alpha$-glucosidase inhibitor, and/or pioglitazone), whole body glucose clearance decreased by $33 \%(5.07 \pm 0.33 \mathrm{ml} /$ $\mathrm{kg} / \mathrm{min}, \mathrm{p}<0.01$ ) compared with control (Table 1), while no change of serum insulin level (mean of $1,2 \mathrm{~h}$ ), indicating the presence of insulin resistance. Accelerating or deteriorating factor [4] for Corona 19 , observed in comorbid obesity, HT [2], diabetes [5], cardiovascular [6] disease and aged subjects, seems to be attributable to the common diminished good insulin action revealed by a decreased whole body glucose clearance. This corresponds to the IGT or diabetes, but here I like to propose inappropriate insulin syndrome including impaired good insulin action and possible compensated excessive bad action of insulin. Excessive bad insulin action has not been proven in Corona19, but impaired good insulin action seems to be certain due to the endothelial dysfunction, under which insulin cannot reach to its receptor, and is also known to be present in diabetes and cardiovascular diseases. One of the major function of endothelium, NO formation is supported with insulin action [7], NK cell which counteracts against Corona 19, requires insulin action8) and acquired activity of immunoreaction of $\mathrm{T}$ cell is also under insulin control.

The most effective ways to keep basic good insulin action are proper body shape (waist, male below $85 \mathrm{~cm}$, female $80 \mathrm{~cm}$ ) with BMI below 23, active physical activity more than 8000 walks per day or exercise habit (sports for all, Tokyo Olympic is a symbol!), proper lifestyle including no smoking and adequate sleep, modest alcohol and nutritionally supported healthy dietary habit. In addition to the above basic achievements proper drugs or catheter intervention would be provided to control blood glucose, pressure, lipids and cardiovascular stenosis, leading to the normalization of appropriate insulin action. Accelerating factor for Corona 19, can be screened using standard cookie test (IGT, Diabetic) and is categorized as inappropriate insulin syndrome. For the mildly hyperglycemic Corona case, early use of small dose of DPP-4 inhibitor or pioglitazone $[8,9]$, which suggests having favorable effect upon endothelial dysfunction in diabetes.

Table 1: Estimated glucose clearance in normal and type 2 diabetes treated with basic hypoglycemic agents (Mean \pm SE).

\begin{tabular}{|c|c|c|c|c|c|c|c|c|c|}
\hline & N & M/F & Age Years & BMI & $\begin{array}{c}\text { FPG } \mathbf{~ m M} \\
\text { HbA1c }\end{array}$ & TG(mM) & $\begin{array}{c}* \text { SSPG } 2 \mathbf{h P G} \\
\text { (mM) }\end{array}$ & $* *$ Insulin(pmol/I) & GC(ml/kg/min) \\
\hline Control & 18 & $16 / 2$ & $69.1 \pm 9.64$ & $22.33 \pm 065$ & $5.86 / 5.6$ & $0.755 \pm 0.15$ & $8.17 \pm 0.49$ & $255 \pm 4.37$ & $7.5 \pm 0.64$ \\
\hline Type 2 DM & 7 & $5 / 2$ & $5 / 2$ & $23.1 \pm 0.4$ & $6.04 / 6.2$ & $0.569 \pm 0.15$ & $10.64 \pm 0.82 \star$ & $220.4 \pm 6.41$ & $5.07 \pm 0.33 \star \star$ \\
\hline
\end{tabular}

\section{$\star \mathrm{P}<0.03$ vs control}

In order to locate the decreased good action of insulin, simplified insulin suppression test [2] using Sand statin combined use of the Cookie meal gives the whole body (4h), muscle (2h) and the difference corresponding to the hepatic glucose clearance against exogenous insulin. This reveals the presence of insulin resistance known in obesity and metabolic syndrome. Compensated hyperinsulinemia accelerates bad action of insulin, enhanced renal $\mathrm{Na} \&$ uric acid reabsorption leading to hypertension and hyperuricemia. Excessive synthesis of fatty acid and cholesterol in liver together with inhibited VLDL release leading to NAFLD and proliferation of arterial smooth muscle cells causing atherosclerosis are categorized in a bad action of insulin. Alzheimer's disease includes both diminished good and excessive bad action of insulin as a causative factor. Inappropriate insulin syndrome includes obesity, metabolic syndrome, and possibly Corona 19, CKD, osteoporosis, COPD, disorder syndrome of basic lifestyle activities (frail ,sarcopenia, locomotive syndrome). Impaired early phase insulin secretion $(\Delta \mathrm{I} / \Delta \mathrm{G}$ at $1 \mathrm{~h})$ or delayed hyperinsulinemia $(2 \mathrm{~h})$ may contributes to the diminished good or excessive bad action of insulin. Impaired good insulin action might be signaled through
IRS2, and the excessive bad action through IRS-1 [10], which lacks resistance in its action.

\section{Acknowledgment}

Deep appreciation is made for Sanwa Kagaku Kenkyusho , who understands the various Insulin Actions and its related disorders and grants (The Japan Research Foundation for Healthy Aging) for Cookie meal Clinical Research.

\section{References}

1. Harada M, Harano Y, Kojima H, Suzuki M, Furusawa, et al. (1987) Computerized glucose clamp method for the determination of insulin sensitivity in diabetic subjects. Jpn J Med 26(1): 25-30.

2. Koyama Y, Kodama K, Suzuki M, Harano Y (2002) Improvement of insulin sensitivity by a long-acting nifedipine preparation (nifedipine-CR) in patients with essential hypertension. Am J Hypertens 15(11): 927-931.

3. Harano Y, Ohgaku S, Kosugi KH, Shibachi M, Adachi T (2006) Development of cookie test for the simultaneous determination of glucose intolerance, hyperinsulinemia, insulin resistance and postprandial dyslipidemia. Endocrine J 53(2): 173-280.

4. Hussain A, Mahawar K, Xia Z, Yang W, El Hasani S (2020) Obesity and mortality of COVID-19 Meta-analysis. Obes Res Clin Pract 14(4): 295300. 
5. Harano Y, Ohgaku S, Hidaka HJ (1977) Glucose, insulin and somatostatin infusion for the determination of insulin sensitivity. J Clin Endocrinol Metab 45(5): 1124-1127.

6. Shinozaki K, Suzuki M, Ikebuchi M, Takaki H, Hara Y (1996) Demonstration of insulin resistance in coronary artery disease documented with angiography. Diabetes Care 19(1): 1-7.

7. A Alijada, P Dandona (2000) Effect of insulin on human aortic endothelial nitric oxide synthase. Metablism 49(2): 147-150.

8. Jung Hye Kim, Kahui Park, Sang Bae Lee (2012) Relationship between natural killer cell activity and glucose control in patients with type 2 diabetes and prediabetes. Pharmacol Rep 64(1): 150-156.

\section{ISSN: 2574-1241}

DOI: 10.26717/BJSTR.2021.34.005568

Y Harano. Biomed J Sci \& Tech Res

(c) This work is licensed under Creative

Submission Link: https://biomedres.us/submit-manuscript.php
9. Suzuki M, Takamisawa I, Yoshimasa Y, Harano Y (2007) Association between insulin resistance and endothelial dysfunction in type 2 diabetes and the effects of pioglitazone. Diabetes Res Clin Pract 76(1): 12-17.

10. Kubota N (2008) Dynamic functionl relay between insulin receptor substrate 1 and 2 in hepatic insulin signaling during fasting and feeding. Cell Metab 8(1): 49-64.

$\begin{array}{ll}\text { BIOMEDICAL } & \text { Assets of Publishing with us } \\ \text { RESEARCHES } & \text { - Global archiving of articles } \\ & \text { - Immediate, unrestricted online access } \\ & \text { - Rigorous Peer Review Process } \\ & \text { - Authors Retain Copyrights } \\ \end{array}$

